\title{
Focus group research in family planning and reproductive health care
}

\author{
Edwin van Teijlingen, Emma Pitchforth
}

\section{Introduction}

This paper discusses how to conduct focus groups in family planning and reproductive research and follows a four-part series outlining the general principles of qualitative research. ${ }^{1-4}$ Originating in market research and through development as a more general social science research method, focus groups now have wide application in many areas of research including health and health care..$^{5}$ Focus groups are often regarded as a quick and convenient way to collect data from several people simultaneously, ${ }^{6}$ but this is an oversimplification. Our paper considers the reasons for choosing to use focus groups and the strengths and weaknesses of the focus group method. Moreover, it highlights some of the practical issues in planning and conducting focus groups, as well as particular considerations in the analysis and presentation of focus group data.

\section{Use of focus groups}

Qualitative methods have a wide range of possible use in family planning and reproductive health care research and focus groups in particular offer great flexibility. ${ }^{1,7}$ Focus groups can stand on their own as a research method or can be used in conjunction with other qualitative methods, such as interviews, ${ }^{8}$ or with quantitative methods, for example, in the development of questionnaires. ${ }^{9}$ Macnaghten and Myers ${ }^{10}$ suggested that "focus groups work best for topics people could talk about to each other in their everyday lives - but don't". Even when participants already know each other, the issues discussed in focus groups may never arise in everyday interactions 11 and, contrary to instinct, focus groups can often provide a forum where participants feel more comfortable discussing sensitive issues compared to one-to-one interviews. ${ }^{12}$ In a focus group, the researcher is outnumbered and no longer at the centre of the process. Group members stimulate each other to think more deeply about the topics and produce answers that may be challenged by others.

Focus groups are not simply an opportunity to interview several people at once. The dynamics of the focus group and interaction among participants is key. Focus groups can be seen as a site of constant negotiation of meanings, identities and stances over a limited period of time. ${ }^{13}$ The interaction within a focus group is seen as a

\section{J Fam Plann Reprod Health Care 2006; 32(1): 30-32 (Accepted 5 October 2005)}

Dugald Baird Centre for Research on Women's Health and Department of Public Health, Medical School, University of Aberdeen, Aberdeen, UK

Edwin van Teijlingen, MEd, PhD, Medical Sociologist/Reader in Public Health

Department of Health Sciences, University of Leicester, Leicester, UK

Emma Pitchforth, BSc, PhD, Lecturer in Social Science and Health

Correspondence to: Dr Edwin van Teijlingen, Department of Public Health and Dugald Baird Centre for Research on Women's Health, University of Aberdeen, Polwarth Building, Medical

School, Foresterhill, Aberdeen AB25 2ZD, UK.

Tel: +44 1224 552495. Fax: +44 1224550529.

E-mail: van.teijlingen@abdn.ac.uk
Box 1: Strengths and weaknesses of the focus groups method

Strengths

- Nobody has to speak on every issue

- Responses are prompted by group members

- Exposes participants to a range of opinions

- Deliberation in group discussion (i.e. the more extreme first answers may be moderated)

Cost-effective compared to one-to-one interviews

- Semi-structured research environment

- Opportunity for follow-up and probing by facilitator and group

- Helps develop theory

Weaknesses

- Expensive

- Getting participants together/organising meeting is time consuming

- Can be dominated be group members with strong personality, opinion or just 'loud' voice

- Needs a skilled facilitator

- Compared to conducting interviews there is less time for each individual to express ideas

- Risk of ending up with conformity: minority views might not be expressed, or not be presented as strongly, as they might be in an interview

source of data and this distinguishes it from other group methods such as Delphi groups. ${ }^{14}$ The Delphi method is used to obtain attitudes and beliefs about an issue without the need for panel members to attend a meeting. ${ }^{15}$ Thus, group discussion "may uncover motivations that would not emerge in individual interviews. Moreover, group discussion may be better able to reveal intensity of feelings, thus facilitating comparisons among different positions". 16

Some of the main strengths and weaknesses of focus groups are summarised in Box 1. Weaknesses such as expense, time and the need for a skilled facilitator highlight the importance of good planning and preparation to enable the researcher and participants to get the most from any focus group.

\section{Planning a focus group}

While group interaction is one of the advantages of focus groups, it can also be a limitation. One or more talkative and/or opinionated individual(s) can dominate the group. Or, as is more often the case, some participants in the group may be very quiet and reluctant to speak. It is difficult to predict how the interaction will work, but a number of factors should be taken into account when organising a focus group.

\section{Participants/group composition}

Overall, focus groups should be large enough to include people with a range of viewpoints, but small enough to allow participants to interact. ${ }^{16}$ A person talking about one aspect of the topic under debate can trigger off ideas (i.e. prompting) in other group members who, like the facilitator, might not have thought about it. It also offers a platform to argue, correct or respond to comments made by others. In a wider sense, for the participant who is talking it offers a plausible audience that consists of more than just the researcher. Different authors have recommended slightly different minimum and maximum numbers. For example, focus groups may comprise six to eight participants each ${ }^{17}$ or "eight to ten individuals". ${ }^{18}$ Rather than adhering to a prescribed number of participants, the 
main consideration should be for a minimum number of participants to generate group discussion, but not so many as to prevent the quieter ones from participating and make the discussion difficult to facilitate.

Focus group participants commonly have shared characteristics, for example, women with recent experience of maternity services or people in the same profession. ${ }^{19}$ These can be drawn from pre-existing groups, such as community groups, or brought together solely for the purposes of the research. The advantage of using a preexisting group is that if participants already know each other they may feel more at ease to take an active part in the discussion and contradict each other. Conversely, people who know each other and work together on a dayto-day basis might not speak openly about thorny issues concerning their group. This could be a particular limitation if the focus group is centred on work- and management-related issues among professionals. More generally, participants in focus groups often experience pressure towards consensus and unanimity, ${ }^{20}$ and this effect may be exacerbated amongst people working together, who are expected to adhere to a common professional standard and code of ethics.

It is easier to organise focus groups with pre-existing groups where one member can contact others. The focus group can also be organised at a convenient time when the group would normally meet. Otherwise there may be problems with getting people to attend at the same place and time or having to attend a specially convened session.

\section{Setting}

Studies have shown that successful focus groups are those that are relaxed and take place in a comfortable setting, sitting in a circle in order to establish the right atmosphere. ${ }^{21,22}$ The facilitator should try to plan the layout and set-up of the group in advance, but this is not always possible. Sometimes the researcher is dependent on the goodwill of others to get focus groups organised (e.g. to invite their colleagues, provide a room or set the time). For example, a health care manager may volunteer to send invitations and book the room, but on arrival the room may turn out to be an office, full of desks, facing a noisy road. As a result, some participants may sit quite far from the microphone, and with the traffic outside, recording can become difficult. Focus groups where the physical constraints of the furniture in the room prevent people from interacting with each other, or where some comments are inaudible, benefit from notes being taken by the facilitator, or when things get really too bad may need to be abandoned.

As with all interview-based research methods, good audio equipment is important. A small tape recorder is usually sufficient (remember to bring spare tapes and batteries) $)^{23}$ but a good table microphone is essential for picking up all voices and digital recorders also offer good sound quality $-\mathrm{a}$ great help when transcribing. Some research facilities have specially adapted rooms with videotape recording of the focus group from various angles to catch all the non-verbal information. Recording by an observer, not the facilitator of the group, is helpful for the transcription and analysis of the recorded material. The observer may be in the same room as the groups or behind one-way glass.

\section{Facilitator}

The focus group facilitator should prepare, with the researchers, areas that they would like the participants to explore, and any particular subjects that might require prompting or encouragement to explore more deeply.
However, there is also the skill of active 'people management', which may involve encouraging quieter group members to contribute while taking the focus away from more dominant members of the group. ${ }^{7}$ The moderator must also maintain a balance between valuing unexpected points raised and refocusing the discussion. ${ }^{24}$ We recommend that it is good practice to have two researchers for one focus group: one as the main facilitator and one to take notes and responsibility for audiotaping, and so on. If the researchers have sufficient time and money to run several focus groups, the facilitator can use the analysis and themes from earlier focus groups to expand the discussion in later groups, exploring particular themes in greater depth.

It has been suggested that the focus group facilitator should be skilled and experienced in conducting such research, ${ }^{25}$ although familiarity with the topic may be equally important. ${ }^{24}$ One of the authors (E.P.) conducted a number of focus groups about the local organisation of maternity care, some jointly with a midwife-researcher who had children, and some with a childless social scientist. The former seemed to have a different rapport with the participants, based on a shared understanding of the world. However, if health professionals are taking the role of group facilitator they must consider how their professional position may influence the group interaction. ${ }^{26}$

\section{Analysis}

In the authors' experience, transcription of focus group interviews generally takes 5-6 hours per hour of recorded tape. Participants are likely to start speaking before others have finished, or several may start talking at the same time. The type of analysis planned may drive the level of detail required for the transcription. For example, if discourse analysis is being used, the detail is paramount and every pause, sigh and interruption must be included. However, this level of detail may not be required for a thematic analysis. Once transcribed, analysis can be by hand or using a computer package that records, codes and enumerates themes. ${ }^{3}$

It is useful to present quotes from a range of focus groups, if possible from all, but it is widely recognised that some present richer data than others. Typically quotes include different voices, for example, a quote from a focus group with women about availability of family planning services in their community (Box 2).

\section{Conclusions}

Focus groups play a growing role in family planning and reproductive health care research. They offer a means of exploring often-sensitive topics that participants may not usually discuss, and can be used on their own or in conjunction with other methods. Despite the strengths of

\begin{tabular}{|c|c|}
\hline \multicolumn{2}{|c|}{ Box 2: Example of a quotation from a focus group transcript } \\
\hline Facilitator: & $\begin{array}{l}\text { Where would you go for advice on STIs, if you were } \\
\text { worried? }\end{array}$ \\
\hline Participant 1: & I would go to my GP, she's really ... [interrupted] \\
\hline Participant 3: & I don't...[interrupted] \\
\hline Participant 2: & $\begin{array}{l}\text { Oh, no I would never go to that doctor, I would go to } \\
\text { the family planning clinic in .... [name removed to } \\
\text { maintain confidentiality] }\end{array}$ \\
\hline Participant 3: & I agree, the GP knows too much about you. \\
\hline Participant 4: & $\begin{array}{l}\text { And my husband is with the same GP. I don't want } \\
\text { him to know. }\end{array}$ \\
\hline Participant 2: & What have you been up to then? [laughter all round] \\
\hline Facilitator: & $\begin{array}{l}\text { So what would you say are the main differences } \\
\text { between going to the GP rather than the family } \\
\text { planning clinic? }\end{array}$ \\
\hline
\end{tabular}




\section{QUALITATIVE RESEARCH/BOOK REVIEWS}

the method, it is folly to think that they are an easy alternative to one-to-one interviews. Focus groups can be expensive, time consuming and difficult to organise and conduct. However, strengths of the focus group method are flexibility, and the ability to gather information from several people at the same time. As such, this paper does not seek to give a recipe for running a successful focus group, but rather outlines issues for consideration when planning, conducting and analysing focus groups.

\section{Statements on funding and competing interests}

Funding. None identified.

Competing interests. None identified.

References

1 Teijlingen ER, Forrest K. The range of qualitative research methods in family planning and reproductive health care. J Fam Plann Reprod Health Care 2004; 30: 171-173.

2 Forrest Keenan K, van Teijlingen ER. The quality of qualitative research in family planning and reproductive health care. J Fam Plann Reprod Health Care 2004; 30: 257-259.

3 Forrest Keenan K, van Teijlingen ER, Pitchforth E. The analysis of qualitative research data in family planning and reproductive health care. J Fam Plann Reprod Health Care 2005; 31: 40-43.

4 Pitchforth E, Porter M, van Teijlingen ER, Forrest Keenan K. Writing up and presenting qualitative research in family planning and reproductive health care. J Fam Plann Reprod Health Care 2005; 31: $132-135$.

5 Learmonth A, Cheung P. Evidence-based health promotion: the contribution of qualitative social research method. Int $J$ Health Promot Educ 1999; 37: 11-15.

6 Kitzinger J. Introducing focus groups. BMJ 1995; 311: 299-302.

7 Wilkinson S. Focus group research. In: Silverman D (ed.), Qualitative Research: Theory, Method and Practice. London, UK: Sage Publications, 2004

8 Dreery R. An action-research study exploring midwives' support needs and the affect of group clinical supervision. Midwifery 2005; 21:161-176.

9 McKinley RK, Manku-Scott,T, Hastings AM, French DP, Baker R. Reliability and validity of a new measure of patient satisfaction with out of hours primary medical care in the UK: development of a patient questionnaire. BMJ 1997; 314: 193
10 Macnaghten P, Myers G. Focus groups. In: Seale C, Giampietri G, Jaber F, Silverman D (eds), Qualitative Research Practice. London, UK: Sage Publications, 2004; 65.

11 Warr RJ. "It was fun ... but we don't usually talk about these things": analyzing sociable interaction in focus groups. Qual Inquiry 2005; 11: 200-225

12 Williams A, Lavender T, Rickmond DH, Tincello DG. Women's experiences after a third-degree obstetric anal sphincter tear: a qualitative study. Birth 2005; 32: 129-136.

13 Crossley ML. 'Could you please pass one of those health leaflets along?': exploring health, morality and resistance through focus groups. Soc Sci Med 2002; 55:1471-1483.

14 Morgan DL. Focus groups. Annu Rev Sociol 1996; 22: 129-152.

15 Ryan M, Scott DA, Reeves C, Bate A, van Teijlingen ER, Russell EM, et al. Eliciting public preferences for healthcare: a systematic review of techniques. Health Technol Assess 2001; 5: 1-186. http://www.ncchta.org/fullmono/mon505.pdf. [Accessed 8 September 2005].

16 Corbetta P. Social Research: Theory, Methods and Techniques. London, UK: Sage Publications, 2003; 276.

17 Tang KC, Davis A. Critical factors in the determination of focus group size. Fam Pract 1995; 12: 474-475.

18 Fitzpatrick R, Boulton M. Qualitative methods for assessing health care. Qual Health Care 1994; 3: 107-113.

19 Gogna M, Romero M, Ramos S, Petracci M, Szulik D. Abortion in a restrictive legal contest: the views of obstetrician-gynaecologists in Buenos Aires, Argentina. Reprod Health Matters 2002; 10: 128

20 Merton GB, Levine RJ, Koocher, GP, Rosenthal R, Thompson WC. Community consultation in socially sensitive research: lessons from clinical trials for treatment for AIDS. Am Psychol 1998; 43: 573-581.

21 Kitzinger J. The methodology of focus groups. Sociol Health Illn 1994; 16: 103-121.

22 Robinson N. The use of focus group methodology - with selected examples from sexual health research. J Adv Nurs 1999; 29: 905-913.

23 Preston C, Keane M, Cheater F. All you ever needed to know about running focus groups but were afraid to ask. Audit Trends 1995; 3: $140-143$.

24 Peterson-Sweeney K. The use of focus groups in pediatric and adolescent research. J Pediatr Health Care 2005; 19: 104-110.

25 Nyamathi A, Shuler P. Focus group interview: a research technique for informed nursing practice. J Adv Nurs 1990; 15: 1281-1288.

26 Reventlow S, Tulinius C. The doctor as focus group moderator shifting roles and negotiating positions in health research. Fam Pract 2005; 22: 335-340. DOI: 10.1093/fampra/cmi003. [Accessed 8 September 2005]

\section{Book Reviews}

You Don't Really Know Me: Why Mothers and Daughters Fight and How Both Can Win. T Apter. New York, NY: W W Norton \& Co., 2005. ISBN: 0-393-32710-8. Price: £8.99. Pages: 256 (paperback)

The promise of an answer to the eternal question "Why do we fight?" and, possibly more importantly, "How we both can win", drew me, a teenage daughter myself, immediately to Terri Apter's latest work.

Throughout the teenage years, the relationship between mother and daughter changes, with new and unheard of levels of stress resulting in mothers and daughters being the child-parent pair that fight most often. Apter attempts to address why such tensions arise and helps to guide both mother and daughter in negotiating their new relationship.

I found that much of the advice was somewhat obvious. Any daytime television psychologist can tell you that with better communication and listening more carefully to the other person your relationship will improve. However, when you are actually in the intense situation of mother-daughter conflict the obvious can be the hardest thing to see. The objective voice of an outsider was both refreshing and enlightening. Apter writes from her perspective as mother of a teenage daughter and also from her memories of being a teenager herself, allowing her to tread carefully and sensitively. This results in a fresh, accepting and non-judgemental, truly helpful book.
I found the insight into mothers and peoplewomen invaluable. I agree that as teenagers we can be consumed in our own world, obsessing over and revolving around ourselves. Being shown that our mothers have needs and weaknesses too was a welcome reminder. For example, in the chapter involving sex, "I know that already" mothers were portrayed as caring people who want to support us emotionally, as opposed to bitter women who want to suppress us physically.

Although I highly doubt that from now on all conflicts with my own mother will result in 'mutual gain', I do sincerely feel that I understand the reasons, motivations and ways in which we can move on and benefit from some of these fights in the future. Terri Apter has succeeded in writing a heartfelt, useful manual for these complicated and difficult relationships, which can be of immense help to mothers and daughters alike, as well as those who work closely with them like guidance teachers, nurses and general practitioners.

Reviewed by Catriona Harvey (aged 17 years) Student, Inverness, UK

Reconceiving Pregnancy and Childcare: Ethics, Experience and Reproductive Labor. A Mullin. New York, NY: Cambridge University Press, 2005. ISBN: 0-521-84438-X. Cost: $£ 15.99$. Pages: 189 (paperback)

This is a book about the ethical aspects of pregnancy, childbirth and childcare. The author is an associate professor of philosophy and writes from the feminist perspective. She looks at the adversarial and negative sides of the topic, such as unwanted pregnancies, and also casts a philosophical eye over the whole spectrum of the reproductive process. Pregnancy is viewed as an important event in itself, not merely for its end result. There are fascinating topical areas such as the chapter discussing the moral status of the fetus. Here various authors are discussed and there is food for thought about one of the most difficult areas in reproductive health care. Inevitably in such a book, there is a chapter entitled 'medicalised model of birth'. The author does, however, add a balanced argument to this chapter, acknowledging that there can be a useful place for medical intervention!

This book also reviews feminist philosophers' writings on motherhood, and introduces the wide diversity of viewpoints. Wellreferenced text demonstrates and analyses different standpoints. In this chapter the role of men is also introduced and examined according to different theories. Caring for young children is also subjected to philosophical analysis.

For a reader who is more used to reading about pregnancy, childbirth and childcare in the clinical, sociological or narrative literature this book makes a refreshing and welcome change. It gives an opportunity for the reader to think about these life-changing events from moral and ethical standpoints, and opens the mind to a new way of observing these common yet unique events in a woman's life.

This book is of interest to anyone involved with reproductive health care, whether it be at policy, professional or personal level.

Reviewed by Susan Carr, MRCOG

Consultant in Community Gynaecology, Glasgow, UK 